Pacific Journal of Mathematics

ON CHARACTERIZATIONS OF EXPONENTIAL 


\title{
ON CHARACTERIZATIONS OF EXPONENTIAL POLYNOMIALS
}

\author{
PHILIP G. LAIRD
}

This paper considers some characterizations of exponential polynomials in $C(G)$, the set of all continuous complex valued functions on a $\sigma$-compact locally compact Abelian group $G$. For $f \in C(G), U_{f}$ will denote the subspace of $C(G)$ obtained by taking finite linear combinations of translates of $f$. It is known that $f$ is an exponential polynomial if and only if $U_{f}$ is of finite dimension. Our main result is to show that $f$ is an exponential polynomial when $U_{f}$ is closed in $C(G)$ if $C(G)$ is given the topology of convergence uniform on all compact subsets of $G$.

Further characterizations of exponential polynomials are given when $G$ is real Euclidean $n$-space, $R^{n}$.

A function $b \in C(G)$ is additive if $b(x+y)=b(x)+b(y)$ for all $x, y \in G$ and $g \in C(G)$ is an exponential if $g(x+y)=g(x) g(y)$ for all $x, y \in C(G)$. An exponential polynomial is a finite linear combination of terms $h=b_{1}^{q_{1}} b_{2}^{q_{2}} \cdots b_{m}^{q_{m}} g$ where $b_{1}, b_{2}, \cdots, b_{m}$ are additive, $q_{1}, q_{2}, \cdots, q_{m}$ are nonnegative integers and $g$ is an exponential.

If $f$ is an exponential polynomial, it is easy to see that $U_{f}$ is finite dimensional. For if $h$ is as above, then $T_{\alpha} h: x \rightarrow h(x-\alpha)$ is a finite linear combination of terms $b_{1}^{r_{1}} b_{2}^{r_{2}} \cdots b_{m}^{r_{m}} g$ for each $\alpha \in G$ where $r_{j}=0,1, \cdots, q_{j}$ for $j=1,2, \cdots, m$. A result of Engert [5] shows that if $U_{f}$ is finite dimensional, then $f$ is an exponential polynomial. The proof of this result when $G$ is any $\sigma$-compact locally compact Abelian group is naturally more involved than when $G$ is merely $R$ or $R^{n}$. Proofs for the case of $C(R)$ may be found in Anselone and Korevaar [1] and Loewner [8] who also refers to $C\left(R^{n}\right)$.

Throughout this paper, the only topology considered on $C(G)$ is that of convergence uniform on all compact subsets of $G$. With $G$ being $\sigma$-compact, let $G$ be the countable union of compact sets $K_{p}$. Let $S_{p}(f)=\sup \left\{|f(x)|: x \in K_{p}\right\}$ and $d(f, g)=\sum_{p=1}^{\infty} 2^{-p} \min \left(1, S_{p}(f-g)\right)$ for $f, g \in C(G)$. Then $d$ is a metric for $C(G)$ and $C(G)$ is complete in this metric.

With such a topology for $C(G)$, if $U_{f}$ is finite dimensional, it is closed. The converse to this is shown here (Theorem 3) so that in $C(G)$,

$f$ is an exponential polynomial $\Longleftrightarrow U_{f}$ is finite dimensional $\Longleftrightarrow U_{f}$ is closed in $C(G)$. 
In showing that when $U_{f}$ is closed, it is then finite dimensional, the following notation shall be used throughout. As above, assume that $G=\bigcup_{p=1}^{\infty} K_{p}$ where each $K_{p}$ is compact. For a given function $f$ in $C(G)$, set

$$
S_{p}=\left\{g \in C(G): g=\sum_{k=1}^{p} a_{k} T_{\beta_{k}} f\right.
$$

$$
\text { where } \left.\left|a_{k}\right| \leqq p \text { and } \beta_{k} \in K_{p} \text { for } k=1,2, \cdots, p\right\} \text {. }
$$

It is clear that $U_{f}=\bigcup_{p=1}^{\infty} S_{p}$. The method of proof is one suggested by Edwards [4], pages 38-39 in establishing the result for functions on the circle group.

\section{Lemma 1. $S_{p}$ is pointwise equicontinuous in $C(G)$.}

Proof. Let $x \in G$ and $\varepsilon>0$. Let $B$ denote the set of all neighborhoods of 0 in $G$. It suffices to show that there is a $U \in B$ such that

$|f(x-\alpha)-f(y-\alpha)|<\varepsilon / p^{2}$ for all $\alpha \in K_{p}$ and all $y$ with $y-x \in B$.

Then

$$
|g(x)-g(y)|<\sum_{k=1}^{p}\left|a_{k}\right| \varepsilon / p^{2} \leqq \varepsilon
$$

whenever $y-x \in U$ and $g \in S_{p}$.

Set $F=x-K_{p}$ so if $\alpha \in K_{p}, \beta=x-\alpha \in F$. For each $\beta \in F$, there exists $V_{\beta} \subset B$ such that $|f(z)-f(\beta)|<\varepsilon / 2 p^{2}$ whenever $z-\beta \in V_{\beta}$. For this $V_{\beta}$, there is a $W_{\beta} \in B$ such that $W_{\beta}+W_{\beta} \subset V_{\beta}$. With $\left\{\beta+W_{\beta}: \beta \in F\right\}$ forming an open cover for the compact set $F$, select a finite subcover $\left\{\beta_{j}+W_{\beta_{j}}\right\}_{j=1}^{m}$. Let $W=\bigcap_{j=1}^{m} W_{\beta_{j}}$ and $U=$ $W \cap(-W)$ so $U \in B$. If $\alpha \in K_{p}$ and $x-\alpha \in F, x-\alpha \in \beta_{l}+W_{\beta_{l}}$ say. Then

$$
y-\alpha=y-x+x-\alpha \in U+x-\alpha \subset \beta_{l}+V_{\beta_{l}}
$$

which also contains $x-\alpha$. Hence $f(x-\alpha)$ and $f(y-\alpha)$ differ from $f\left(\beta_{l}\right)$ by amounts in modulus less than $\varepsilon / 2 p^{2}$ and the result follows.

LEMMA 2. $S_{p}$ is compact in $C(G)$.

Proof. Use is made of the condition that in $C(G)$, a closed equicontinuous set $S$ is compact if $S[x]=\{f(x): f \in S\}$ is compact in $C$ (see, for example, [3], page 34 or [6], page 234). With $f$ being continuous and $x \in G,\left\{f(x-\beta): \beta \in K_{p}\right\}$ is compact whence $S_{p}[x]$ is compact in $C$. To show that $S_{p}$ is closed, let $\left\{g_{q}\right\}$ be any Cauchy 
sequence in $S_{p}$ with $g_{q}=\sum_{k=1}^{p} a_{q, k} T_{\beta_{q, k}} f$. Since $\left|a_{q, 1}\right| \leqq p$ for all positive integers $q$, a convergent subsequence $a_{q^{\prime}, 1}$ may be found with limit, say $a_{1}$, and $\left|a_{1}\right| \leqq p$. Continue in this manner to find convergent subsequences $\left\{a_{r, k}\right\}_{r=1}^{\infty}$ for $k=1,2, \cdots, p$ with respective limits $a_{k}$ where $\left|a_{k}\right| \leqq p$. Now use $\left\{\beta_{r, k}\right\}_{r=1}^{\infty} \subset K_{p}$ for $k=1,2, \cdots, p$ and $K_{p}$ is compact to find convergent subsequences $\left\{\beta_{v, k}\right\}_{v=1}^{\infty}$. With $a_{v, k} \rightarrow a_{k}$, $\left|a_{k}\right| \leqq p$ and $\beta_{v, k} \rightarrow \beta_{k} \in K_{p}$ as $v \rightarrow \infty$ for $k=1,2, \cdots, p$, it follows that $g_{v} \rightarrow g$ for some $g \in S_{p}$ So $g_{q} \rightarrow g$ as $q \rightarrow \infty$ showing that $S_{p}$ is closed. Hence $S_{p}$ is compact in $C(G)$.

Theorem 3. If $U_{f}$ is closed in $C(G)$, then $U_{f}$ is finite dimensional.

Proof. Since $U_{f}=\bigcup_{p=1}^{\infty} S_{p}$ is closed in the metric space $C(G)$, it follows by Baire's category theorem applied to $U_{f}$ that there must be as $S_{p}$ that is not nowhere dense. As this $S_{p}$ is closed, it must have a nonvoid interior. Hence $U_{f}$ contains a compact neighbourhood of zero. So, by Riesz's theorem (see, for example [3], page 65) $U_{f}$ is finite dimensional.

The remainder of this article, concerns exponential polynomials in $C\left(R^{n}\right)$. These functions in $C\left(R^{n}\right)$ are finite linear combinations of terms $x_{1}^{p_{1}} x_{2}^{p_{2}} \cdots x_{n}^{p_{n}} \exp \left(a_{1} x_{q}+a_{2} x_{2}+\cdots+a_{n} x_{n}\right) \quad$ where $\quad x=$ $\left(x_{1}, x_{2}, \cdots, x_{n}\right) \in R^{n}, \quad p_{1}, p_{2}, \cdots, p_{n}$ are nonnegative integers and $a_{1}, a_{2}, \cdots, a_{n}$ are complex numbers. In restricting $G$ to be $R^{n}$, little economy of the proof of Theorem 3 is gained except for Lemma 1. However, it is considerably easier to show for $C\left(R^{n}\right)$ compared with $C(G)$ that if $U_{f}$ is finite dimensional, then $f$ is an exponential polynomial. A new and simple proof is as follows.

Suppose that $U_{f}$ has finite dimension $m$ where $m>1$. (If $m=0$, $f=0$ and if $m=1$ a simpler version of the following suffices.) Let $g_{1}, g_{2}, \cdots, g_{m}$ be a basis of $U_{f}$ and $g=\left(g_{1}, g_{2}, \cdots, g_{m}\right)$. Then $T_{\alpha} g=A(\alpha) g$ where $A(\alpha)$ is an $m \times m$ complex matrix. From $T_{\alpha+\beta}=T_{\alpha} T_{\beta}$, one finds that $A(\alpha+\beta)=A(\alpha) A(\beta)$ and $A(0)=I$, the unit matrix. Since $T_{\alpha} f \rightarrow T_{\beta} f$ as $\alpha \rightarrow \beta, A(\alpha)$ is continuous. So $z \in R^{n}$ near 0 may be chosen and fixed so that $A(z)$ is nonsingular. It is clear from

$$
A(x)=\left(\int_{x_{1}}^{x_{1}+z_{1}} \cdots \int_{x_{n}}^{x_{n}+z_{n}} A(y) d y\right)(A(z))^{-1},
$$

that each partial derivative of $A$ exists. Letting $\left\{e_{1}, e_{2}, \cdots, e_{n}\right\}$ be the standard basis for $R^{n}$,

$$
D_{j} g=\lim _{h \rightarrow 0}\left(A\left(-h e_{j}\right)-A(0)\right) g ! h=C_{j} g,
$$

where the matrix $C_{j}=D_{j} A(0)$. So $D_{j}\left(\exp \left(-C_{j} x_{j}\right) g\right)=0$ showing 
that $g=\exp \left(C_{j} x_{j}\right) \dot{\phi}_{j}$ where $\phi_{j}$ is independent of $x_{j}$ for $j=1,2, \cdots, n$ and $\phi_{j}$ takes value in $R^{m}$.

From $\exp \left(C_{1} x_{1}\right) \phi_{1}=\exp \left(C_{2} x_{2}\right) \phi_{2}$ with $x_{1}=0 \quad \phi_{1}\left(x_{2}, x_{3}, \cdots, x_{n}\right)=$ $\exp \left(C_{2} x_{2}\right) \dot{\phi}_{2}\left(0, x_{3}, x_{4}, \cdots, x_{n}\right)$. Successively equating $\exp \left(C_{j} x_{j}\right) \dot{\phi}_{j}=$ $\exp \left(C_{j+1} x_{j+1}\right) \phi_{j+1}$ with $x_{j}=0$ for $j=1,2, \cdots, n-1$, we find

$$
g=\exp \left(C_{1} x_{1}\right) \exp \left(C_{2} x_{2}\right) \cdots \exp \left(C_{n} x_{n}\right) d
$$

where $d \in R^{n}$ is constant. As it is well known that the elements of $\exp (C x)$ are exponential polynomials in $x$ ([2], page 46), it follows that the components of $g$ are exponential polynomials. Hence $f$ is an exponential polynomial in $C\left(R^{n}\right)$ when $U_{f}$ is finite dimensional.

Other characterizations of exponential polynomials in $C\left(R^{n}\right)$ are now given. For $C(R)$, one such is that of the set of all solutions to all nontrivial linear ordinary differential equations with constant coefficients. For $C\left(R^{n}\right)$ with $n>1$, one cannot identify the set of all exponential polynomials with the set of all solutions to all nontrivial linear partial differential equations with constant coefficients. However, a necessary and sufficient condition that $f \in C\left(R^{n}\right)$ be an exponential polynomial is that there exists $n$ nonzero linear differential operators $L_{j}=L_{j}\left(D_{j}\right)$ with constant coefficients where each $L_{j}$ only involves the $j$ th partial derivative $D_{j}$ and $L_{j} f=0$ for $j=1,2, \cdots, n$. A proof of this given by Laird [7], page 816, is reproduced here for completeness. The necessity of the condition is obvious. Conversely, if $f \in C\left(R^{n}\right)$ and if $L_{1} f=0$, then $f$ is a finite sum of terms $A\left(x_{2}, x_{3}, \cdots, x_{n}\right) x_{1}^{q_{1}} \exp a x_{1}$. With $L_{2} f=0, L_{2} A=0$ and so each $A$ is a finite sum of terms $B\left(x_{3}, x_{4}, \cdots, x_{n}\right) x_{2}^{q_{2}} \exp b x_{2}$. Continuing in this manner, one finds that $f$ is an exponential polynomial.

The following is an extension of the above result.

THEOREM 4. Let $f \in C\left(R^{n}\right)$ and let $A=\left(a_{j_{k}}\right)$ be a real nonsingular $n \times n$ real matrix. Then a necessary and sufficient condition that $f$ be an exponential polynomial is that there exist $n$ nonzero polynomials $P_{1}, P_{2}, \cdots, P_{n}$, each of one variable, such that

$$
P_{j}\left(a_{j_{1}} D_{1}+a_{j_{2}} D_{2}+\cdots+a_{j_{n}} D_{n}\right) f=0
$$

for $j=1,2, \cdots, n$. Then

Proof. Let $u_{k}=\sum_{m=1}^{n} b_{k m} x_{m}$ for $k=1,2, \cdots, n$ and $f(x)=g(u)$.

$$
D_{m} f(x)=\sum_{k=1}^{n} \frac{\partial g}{\partial u_{k}} \frac{\partial u_{k}}{\partial x_{m}}
$$




$$
\sum_{m=1}^{n} a_{j m} D_{m} f=\frac{\partial g}{\partial u_{j}}
$$

when $B=\left(b_{k m}\right)$ is chosen so that $B^{r}=A^{-1}$. The given condition is then $P_{j}\left(D_{j}\right) g=0$ for $j=1,2, \cdots, n$ which is equivalent to $g$ and so to $f$ being an exponential polynomial.

TheOREM 5. Let $a \in R^{n}, f \in C\left(R^{n}\right)$ and $U_{f}(a)$ denote the subspace in $C\left(R^{n}\right)$ obtained from finite linear combinations of terms $f(x-t a)$ for $t \in R$. A necessary and sufficient condition that $f$ be an exponential is that $U_{f}\left(a_{j}\right)$ be finite dimensional for $n$ linearly independent vectors $a_{1}, a_{2}, \cdots, a_{n}$ in $R^{n}$.

Proof. The necessity is easily seen from $U_{f}(a) \subset U_{f}$ for all $a \in R^{n}$, and if $f$ is an exponential polynomial, then $U_{f}$ is finite dimensional.

The converse, which has been recognized by Loewner [8] when $\left\{a_{1}, a_{2}, \cdots, a_{n}\right\}$ is the standard basis, may be shown directly, or as follows. Let $f_{j}(t)=f\left(t a_{j}\right)$ for all $t \in R$ and $j=1,2, \cdots, n$. If each $U_{f}\left(a_{j}\right)$ is finite dimensional in $C\left(R^{n}\right)$, then $U_{f_{j}}$ is finite dimensional in $C\left(R^{n}\right)$. So each $f_{j}$ is an exponential polynomial and there is a nonzero polynomial $P_{j}$ so that $P_{j}(D) f_{j}=0$. With $D f_{j}=a \cdot \operatorname{grad} f$, the conditions of the sufficiency part of Theorem 4 are satisfied. Hence $f$ is an exponential polynomial in $C\left(R^{n}\right)$.

ACKNOWLEDGMents. The author would like to thank Dr. R. V. Nillsen of the University of Wollongong for several helpful discussions and also acknowledge the use of the Science Citation Indices.

\section{REFERENCES}

1. P. M. Anselone and J. Korevaar, Translation invariant subspaces of finite dimension, Proc. Amer. Math. Soc., 15 (1964), 747-752.

2. W. A. Coppel, Stability and Asymptotic Behavior of Differential Equations, Heath, Boston, 1965.

3. R. E. Edwards, Functional Analysis: Theory and Applications, Holt, Rinehart and Winston, New York, 1965.

4. — Fourier Series, A Modern Introduction, Volume II, Holt, Rinehart and Winston, New York, 1967.

5. M. Engert, Finite dimensional translation invariant subspaces, Pacific J. Math., 32 (1970), 333-343.

6. J. L. Kelly, General Topology, Van Nostrand, Princeton, 1955.

7. P. G. Laird, Entire mean periodic functions, Canad. J. Math., 27 (1975), 805-818.

8. C. Loewner, On some transformations invariant under Euclidean or non-Euclidean isometries, J. Math. Mech., 8 (1959), 393-409.

Received January 4, 1977 and in revised form July 12, 1978.

UNIVERSITY OF WOLLONGONG

WOLLONGONG, N. S. W. 2500

Australia 



\section{PACIFIC JOURNAL OF MATHEMATICS}

\section{EDITORS}

RICHARD ARENS (Managing Editor)

University of California

Los Angeles, CA 90024

Charles W. Curtis

University of Oregon

Eugene, OR 97403

C. C. MOORE

University of California

Berkeley, CA 94720
J. DUGUNDJI

Department of Mathematics

University of Southern California

Los Angeles, CA 90007

R. FINN and J. MILGRAM

Stanford University

Stanford, CA 94305

\section{ASSOCIATE EDITORS}

\section{E. F. BeCKENBACH}

B. H. NeumanN

F. WOLF

K. YoSHIDA

\section{SUPPORTING INSTITUTIONS}

\author{
UNIVERSITY OF SOUTHERN CALIFORNIA \\ STANFORD UNIVERSITY \\ UNIVERSITY OF HAWAII \\ UNIVERSITY OF TOKYO \\ UNIVERSITY OF UTAH \\ WASHINGTON STATE UNIVERSITY \\ UNIVERSITY OF WASHINGTON
}

The Supporting Institutions listed above contribute to the cost of publication of this Journal, but they are not owners or publishers and have no responsibility for its content or policies.

Mathematical papers intended for publication in the Pacific Journal of Mathematics should be in typed form or offset-reproduced, (not dittoed), double spaced with large margins. Please do not use built up fractions in the text of the manuscript. However, you may use them in the displayed equations. Underline Greek letters in red, German in green, and script in blue. The first paragraph or two must be capable of being used separately as a synopsis of the entire paper. Items of the bibliography should not be cited there unless absolutely necessary, in which case they must be identified by author and journal, rather than by item number. Manuscripts, in triplicate, may be sent to any one of the editors. Please classify according to the scheme of Math. Reviews, Index to Vol. 39. All other communications should be addressed to the managing editor, or Elaine Barth, University of California, Los Angeles, California, 90024.

50 reprints to each author are provided free for each article, only if page charges have been substantially paid. Additional copies may be obtained at cost in multiples of 50 .

The Pacific Journal of Mathematics is issued monthly as of January 1966. Regular subscription rate: $\$ 72.00$ a year (6 Vols., 12 issues). Special rate: $\$ 36.00$ a year to individual members of supporting institutions.

Subscriptions, orders for numbers issued in the last three calendar years, and changes of address should be sent to Pacific Journal of Mathematics, P.O. Box 969, Carmel Valley, CA 93924, U.S.A. Older back numbers obtainable from Kraus Periodicals Co., Route 100, Millwood, NY 10546.

PUBLISHED BY PACIFIC JOURNAL OF MATHEMATICS, A NON-PROFIT CORPORATION

Printed at Kokusai Bunken Insatsusha (International Academic Printing Co., Ltd.). 8-8, 3-chome, Takadanobaba, Shinjuku-ku, Tokyo 160, Japan. 


\section{Pacific Journal of Mathematics}

\section{Vol. 80, No. $2 \quad$ October, 1979}

K. Adachi, On the multiplicative Cousin problems for $N^{p}(D) \ldots \ldots \ldots \ldots 297$

Howard Banilower, Isomorphisms and simultaneous extensions in $C(S) \ldots 305$

B. R. Bhonsle and R. A. Prabhu, An inversion formula for a distributional

finite-Hankel-Laplace transformation ................... 313

Douglas S. Bridges, Connectivity properties of metric spaces.......... 325

John Patton Burgess, A selection theorem for group actions ........... 333

Carl Claudius Cowen, Commutants and the operator equations

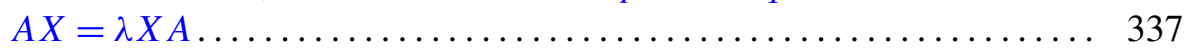

Thomas Curtis Craven, Characterizing reduced Witt rings. II .......... 341

J. Csima, Embedding partial idempotent d-ary quasigroups ............ 351

Sheldon Davis, A cushioning-type weak covering property ............ 359

Micheal Neal Dyer, Nonminimal roots in homotopy trees ............. 371

John Erik Fornaess, Plurisubharmonic defining functions ........... 381

John Fuelberth and James J. Kuzmanovich, On the structure of finitely

generated splitting rings .......................... 389

Irving Leonard Glicksberg, Boundary continuity of some holomorphic

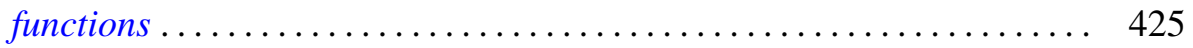

Frank Harary and Robert William Robinson, Generalized Ramsey theory.

IX. Isomorphic factorizations. IV. Isomorphic Ramsey numbers .......

Frank Harary and Allen John Carl Schwenk, The spectral approach to determining the number of walks in a graph...........

David Kent Harrison, Double coset and orbit spaces ..... . .

Shiro Ishikawa, Common fixed points and iteration of commuting

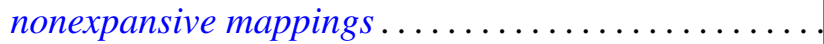

Philip G. Laird, On characterizations of exponential polynomials ........ 503

Y. C. Lee, A Witt's theorem for unimodular lattices ...........

Teck Cheong Lim, On common fixed point sets of commutative

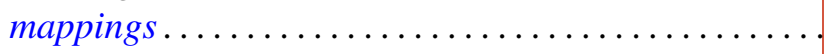

R. S. Pathak, On the Meijer transform of generalized functions ...

T. S. Ravisankar and U. S. Shukla, Structure of $\Gamma$-rings . . .

Olaf von Grudzinski, Examples of solvable and nonsolvable convolution

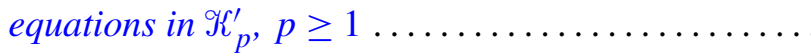

